\title{
Effects of Virus Infection on Susceptibility of Soybean Plants to Phomopsis longicolla
}

\author{
J. P. Soto-Arias and G. P. Munkvold, Department of Plant Pathology, Seed Science Building, Iowa State University, Ames, IA 50011
}

\begin{abstract}
Soto-Arias, J. P., and Munkvold, G. P. 2011. Effects of virus infection on susceptibility of soybean plants to Phomopsis longicolla. Plant Dis. 95:530-536.

Infection of soybean by Bean pod mottle virus (BPMV) or Soybean mosaic virus (SMV) has been reported to increase susceptibility to seed infection by Phomopsis spp., but the mechanism is unclear. Effects of virus infection on susceptibility to Phomopsis longicolla were studied in greenhouse experiments. Three soybean cultivars were inoculated with BPMV at growth stage V2 to V3, and with $P$. longicolla at R3, R5, or R7. Inoculation with BPMV did not increase the incidence of stem infection by $P$. longicolla, but it increased susceptibility to seed infection of cultivars Spansoy 201 at R5, and

observed only in 92M02. Thus, BPMV predisposed soybean plants to seed infection by $P$. longicolla, but this predisposition was not due solely to prolonging maturation. In separate experiments, two soybean cultivars were inoculated with SMV (V2 to V3) and P. longicolla (R3 and R5). Inoculation with SMV did not increase the incidence of stem or seed infection by $P$. longicolla. The SMV-Phomopsis spp. relationship may be cultivar and strain dependent. Results suggest that the risk of soybean seed infection by $P$. longicolla may be higher when BPMV vector populations are high and BPMV infection is widespread.
\end{abstract} Pioneer brand 92M02 at R3, R5, and R7. A delay in maturity was
Soybean (Glycine max (L.) Merr.) is affected by several seedborne pathogens that reduce seed quality $(22,29)$, affecting both marketability $(13,24)$ and germination efficiency $(28,29)$. One of the most common seedborne diseases is Phomopsis seed decay, primarily caused by Phomopsis longicolla T.W. Hobbs $(14,17)$, a member of the Diaporthe-Phomopsis complex (30). Fungi of this complex are widespread throughout most of the soybean producing areas around the world $(21,22)$ and together cause more losses in soybean than any other single fungal disease (30). Seed infection by members of this complex reduces quality of seeds used for planting by causing physical damage $(9,30)$ and reducing germination $(8,20)$. Moreover, severe incidence of seed decay affects the quality of soybean used for processing by altering protein content (22) and reducing oil quality (36). In addition to seed infection, members of this fungal complex can also infect stems, petioles, and pods (17); this phase of the disease can also cause significant yield losses (35).

$P$. longicolla moves from infected pods into seeds, and although pods can be infected at any time after they are formed, the likelihood of seed infection increases at physiological maturity $(17,19)$. Higher incidence of seed decay occurs when there is warm weather during pod development and maturation and harvest is delayed $(27,29)$. Seeds tend to be more susceptible to infection by $P$. longicolla within deteriorated pods, or when plants are deficient in potassium, severely damaged by insects, or infected with one or more viruses $(17,29)$.

Bean pod mottle virus (BPMV) and Soybean mosaic virus (SMV) are the most common viral diseases of soybean $(7,10)$; both reduce yield and impact seed quality $(7,10)$. Both viruses can cause seedcoat mottling $(7,10,13)$, which has a negative impact on the marketability of seeds and food-grade soybean (13). Moreover, SMV infection also reduces seed germination and vigor $(10,16)$, and under certain conditions, BPMV and SMV can affect oil and protein content, nodulation, and nitrogen fixation $(10,39)$.

Corresponding author: G. P. Munkvold, E-mail: munkvold@iastate.edu

Accepted for publication 14 January 2011.

doi:10.1094/PDIS-10-10-0767

(C) 2011 The American Phytopathological Society
In Iowa, Phomopsis spp., BPMV, and SMV have been prevalent in some years, depending on weather conditions during key developmental periods (37). Recently, the frequent detection of $P$. longicolla in stems collected during the Iowa soybean disease survey conducted from 2005 to 2007 (18) coincided with a resurgence in bean leaf beetle (Cerotoma trifurcata Förster) populations (3) and BPMV symptoms (12).

Several reports suggest that seeds from plants infected by either SMV or BPMV are more susceptible to infection by Phomopsis spp. $(1,8,16,32)$; however, the mechanism for this predisposition is unclear. One proposed mechanism for the increased susceptibility to Phomopsis spp. in virus-infected plants is that virus infection extends the length of the late-season growth stage intervals, and therefore, prolongs the exposure of pods and seeds to infection $(1,16)$. Although this mechanism has been proposed, none of the published studies has directly tested this hypothesis.

Stuckey et al. (32) found a consistent significant increase in seed infection by Phomopsis spp. in plants that were infected with BPMV or doubly infected with SMV and BPMV, but not in plants inoculated only with SMV. Other workers have observed significant differences in seed infection by Phomopsis spp. when plants have been inoculated with SMV and Phomopsis spp. $(8,15,16)$. Koning et al. (15) observed lower incidence of seed infection by Phomopsis spp. in SMV-resistant plants, but this effect was more associated with the lack of SMV infection than a direct effect of the SMV resistance alleles.

In field studies, Abney and Ploper (1) demonstrated that infection of pods by Phomopsis spp. was increased by BPMV inoculations, and seed infection was increased only if the virus infection delayed the rate of seed maturation. However, it has also been reported that pod injury caused by $C$. trifurcata allows secondary infection by fungal pathogens such as Alternaria tenuissima (Kunze ex. Pers.) Wilt. and Phomopsis spp. $(23,28,31)$. Therefore, it is not possible to separate confounding effects of beetle activity from a direct BPMV-Phomopsis interaction in experiments conducted under natural field conditions.

The effects of changes in duration of late-season growth stage intervals on $P$. longicolla infection established before pod and seed maturation has not yet been studied. Also, previous studies have not considered the effects of either BPMV or SMV infection on stem infection by $P$. longicolla. A better understanding of the relationship between virus infection and susceptibility to Phomopsis 
seed decay will facilitate the development of integrated management practices that affect all three diseases. The objective of this study was to assess the effects of BPMV and SMV infection on susceptibility of soybean plants to infection by $P$. longicolla at different growth stages.

\section{Materials and Methods}

Inoculation procedures. A preliminary experiment was performed in order to identify an aggressive $P$. longicolla isolate to be used in further experiments. Eleven isolates were obtained from soybean seeds harvested from field trials conducted in 2006 and 2007. These isolates were transferred to potato dextrose broth (PDB) in 1.5-ml tubes and kept for 3 days on a shaker at room temperature to promote colony growth; then tubes were stored at $4^{\circ} \mathrm{C}$ until needed. All isolates were identified as $P$. longicolla by conventional PCR based on the procedure of Zhang et al. (38) with modifications. Fungal mycelia was scraped directly from the surface of PDA cultures, homogenized in the FastPrep Instrument (QBiogene Inc., Carlsbad, CA), and placed into a 1.5-ml microfuge tube with $250 \mu \mathrm{l}$ of extraction buffer. The mixtures were centrifuged and the supernatants were saved as DNA extracts. Soybean plants were individually inoculated with each $P$. longicolla isolate, and stem and seed infection were evaluated as further described below. Based on the results of $P$. longicolla infection obtained from this preliminary experiment (data not shown), isolate $\mathrm{Ph \# 3}$ from Mahaska County, IA, was selected to use in subsequent experiments.

In order to perform $P$. longicolla inoculations, the chosen isolate was transferred from PDB tubes to antibiotic-amended potato dextrose agar (PDA) (200 mg streptomycin sulfate, $50 \mathrm{mg}$ chlortetracycline hydrochloride, $120 \mathrm{mg}$ neomycin sulfate, $39 \mathrm{~g}$ Difco PDA per liter) and allowed to grow for 16 to 36 days in 9-cmdiameter petri dishes. The $P$. longicolla conidial suspension was prepared as described by Rupe and Ferriss (27) with modifications. Each $P$. longicolla culture was flooded with $5 \mathrm{ml}$ of sterile deionized water, and the culture surface was rubbed with a sterile glass spreader to dislodge conidia. The suspension was then filtered through four layers of sterile cheesecloth and placed on a stir plate for 5 to $10 \mathrm{~min}$ to enhance conidial release from pycnidia. Finally, the suspension was diluted with sterile deionized water to give a final concentration of $1 \times 10^{6}$ conidia per $\mathrm{ml}$.

Conidial suspensions were applied onto soybean plants (flowers, pods, and stems) at specific plant growth stages R3 (beginning of pod development) and R5 (beginning of seed development) using a hand-held sprayer until runoff. Plants in treatments that did not include $P$. longicolla inoculations were mock-inoculated with sterile deionized water. In order to keep a humid environment to enhance conditions for infection, plants were covered with plastic bags for 48 to $72 \mathrm{~h}$ following inoculation (to promote pod and stem

Table 1. Analysis of variance (ANOVA) for effects of soybean cultivar, Bean pod mottle virus (BPMV), and Phomopsis longicolla inoculation treatments on infection of stems and seeds by $P$. longicolla ${ }^{\mathrm{a}}$

\begin{tabular}{lccc}
\hline & & \multicolumn{2}{c}{$P$ value } \\
\cline { 3 - 4 } Source & df & Stems & Seeds \\
\hline Repetition & 1 & 0.722 & 0.328 \\
Block $_{\text {Cultivar }^{b}}$ & 4 & 0.969 & 0.085 \\
BPMV $^{c}$ & 1 & 0.157 & $<0.05$ \\
$P$. longicolla & 1 & 0.184 & $<0.05$ \\
Cultivar $\times$ BPMV & 2 & $<0.05$ & $<0.05$ \\
Cultivar $\times$ P. longicolla & 1 & 0.133 & 0.593 \\
BPMV $\times$ P. longicolla & 2 & 0.075 & $<0.05$ \\
Cultivar $\times$ BPMV $\times$ P. longicolla & 2 & 0.440 & $<0.05$ \\
\hline
\end{tabular}

${ }^{a}$ Data are from two repetitions of a greenhouse experiment.

${ }^{b}$ Two cultivars tested: Spansoy 201 and Colfax.

${ }^{c}$ BPMV treatments: inoculated or noninoculated.

${ }^{\mathrm{d}}$ P. longicolla treatments: Inoculation at growth stage R3 or R5 and noninoculated. infection) and again when they reached $\mathrm{R} 7$ growth stage (to induce movement of the fungus from pods to seeds). The soybean growth stage was defined as previously described (5), and plants were visually evaluated and specific vegetative or reproductive stages were determined when $50 \%$ or more of the plants were in that stage.

Virus inoculum was maintained by continuous greenhouse transfers using mechanical inoculations and frozen and stored infected leaves. A BPMV subgroup II isolate was obtained from symptomatic plants collected from the field in Iowa. This isolate was also used in a previous study (4). A non-aphid-transmissible isolate of SMV-G2 was kindly provided by A. Eggenberger, Iowa State University. Inoculum was prepared by grinding infected leaves with sterilized pestles and mortars in chilled Agdia extraction buffer (Agdia, Inc., Elkhart, IN). To inoculate plants, the inoculum was rubbed with the index finger onto Carborundum-dusted leaf surface of plants at growth stage V2 to V3 (second to third trifoliolate). Virus symptoms were observed 25 to 30 days after inoculation. Plants of treatments that did not include virus inoculation were mock-inoculated with Agdia general extraction buffer at the same growth stage.

Greenhouse studies. Experiments were conducted in 2009 and 2010 at the plant pathology greenhouse facilities at Iowa State University in Ames. The effect of BPMV inoculations on infection by $P$. longicolla was studied in three experiments. Each experiment was conducted twice, and the experimental design was a randomized complete block with five replications of two plants.

In the first BPMV-Phomopsis experiment, treatments were in a $2 \times 2 \times 3$ factorial, with two soybean cultivars, two virus treatments, and three $P$. longicolla treatments.

Two Maturity Group II soybean cultivars were chosen: Spansoy 201 (Spangler Seed Tech, Inc., Jefferson, WI) and Colfax (University of Nebraska, Lincoln, NE). Spansoy 201 is tolerant to BPMV but susceptible to SMV, while Colfax is susceptible to BPMV but tolerant to SMV (11). Both cultivars are also susceptible to infection by Phomopsis spp. The two virus treatments were inoculated and noninoculated (mock inoculated), and the three P. longicolla treatments consisted of inoculations at growth stage R3, R5, and noninoculated (mock inoculated). Virus and $P$. longicolla inoculations were performed as described above. The first repetition of the experiment was planted on 11 March 2009. Inoculations with $P$. longicolla were carried out at R3 and R5 on 21 May and 12 June, respectively. Plants were harvested on 1 July (Spansoy 201) and 22 July (Colfax) 2009. The second repetition was planted on 3 August 2009. Inoculations with $P$. longicolla were carried out at R3 and

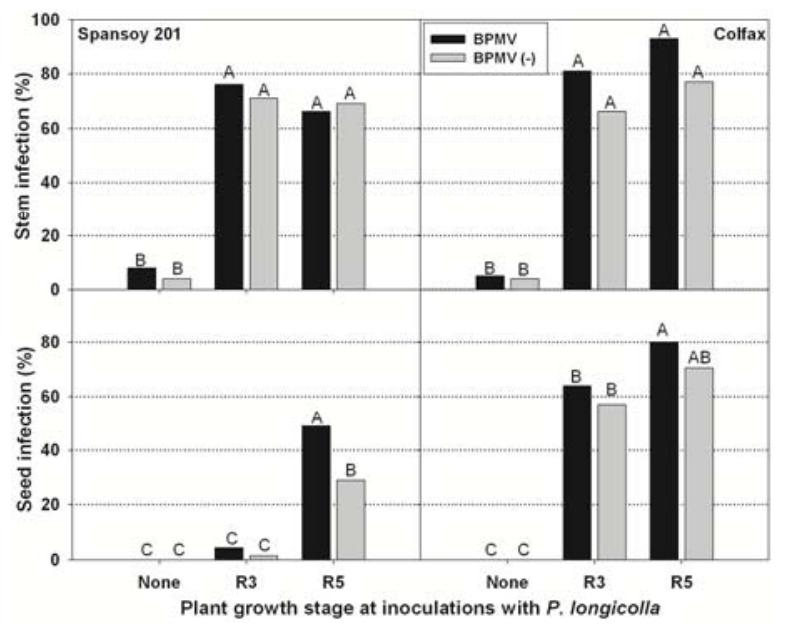

Fig. 1. Effects of Bean pod mottle virus (BPMV) and Phomopsis longicolla inoculation treatments on infection of stems (top) and seeds (bottom) by P. longicolla of two soybean cultivars, BPMV-tolerant Spansoy 201 (left) and BPMVsusceptible Colfax (right) at different plant growth stages. Within each cultivar, means labeled with the same letter were not significantly different according to Tukey's test $(P<0.05)$. 
R5 on 25 September and 20 October 2009, respectively. Plants were harvested on 19 November (Spansoy 201) and 3 December (Colfax) 2009. The two cultivars were harvested at different times in both repetitions of the experiment because of differing cultivar maturities.

Two further experiments were conducted under the same conditions, following the same inoculation procedures, and using the Maturity Group II cultivar 92M02 (Pioneer Hi-Bred Int., Inc., Des

Table 2. Analysis of variance (ANOVA) for effects of Bean pod mottle virus (BPMV) and Phomopsis longicolla inoculation treatments on infection of stems and seeds by P. longicolla of soybean cultivar 92M02

\begin{tabular}{lcccccc}
\hline & & \multicolumn{4}{c}{$P$ value } \\
\cline { 3 - 4 } & & \multicolumn{2}{c}{ Experiment 1 } & & \multicolumn{2}{c}{ Experiment 2a } \\
\cline { 3 - 4 } \cline { 6 - 7 } Source & df & Stems & Seeds & & Stems & Seeds \\
\hline Repetition & 1 & $<0.05$ & 0.325 & & 0.859 & 0.054 \\
Block & 4 & 0.928 & 0.967 & & 0.402 & 0.800 \\
BPMV $^{\mathrm{b}}$ & 1 & 0.214 & $<0.05$ & & 0.098 & $<0.05$ \\
$P$. longicolla & 2 & $<0.05$ & $<0.05$ & & $<0.05$ & $<0.05$ \\
BPMV $\times$ P. longicolla & 2 & 0.682 & $<0.05$ & & 0.329 & $<0.05$ \\
\hline
\end{tabular}

${ }^{\text {a }}$ Experiment 1 and experiment 2 were conducted twice, and data from both repetitions of each experiment were pooled.

b BPMV treatments: inoculated or noninoculated.

${ }^{c} P$. longicolla treatments: experiment 1 , inoculation at growth stage $\mathrm{R} 3$ or R5 and noninoculated; experiment 2, inoculation at growth stage R5 or R7 and noninoculated.
Moines, IA), susceptible to BPMV and Phomopsis spp. Treatments were in a $2 \times 3$ factorial, with two virus treatments and three $P$ longicolla treatments. In both experiments, the two virus treatments were BPMV-inoculated and noninoculated. Treatments

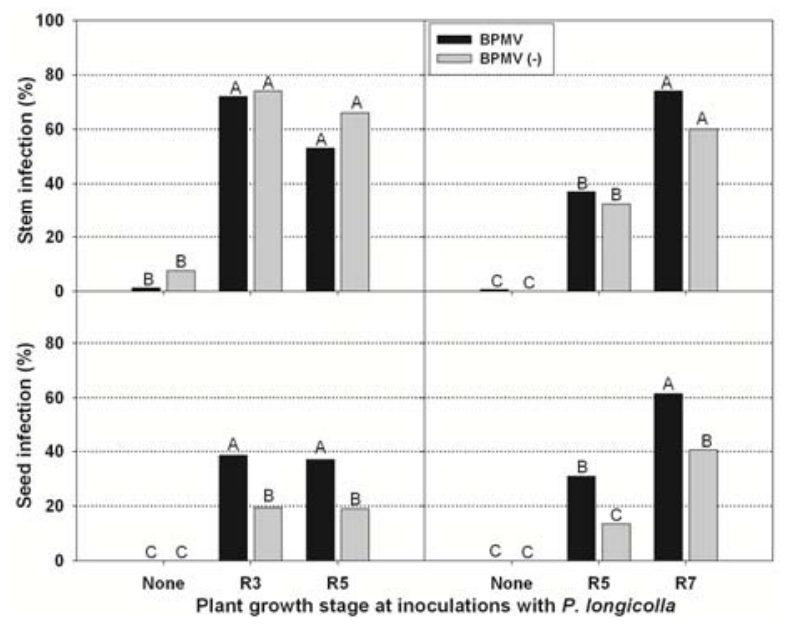

Fig. 2. Effects of Bean pod mottle virus (BPMV) and Phomopsis longicolla inoculation treatments on infection of stems (top) and seeds (bottom) by $P$. longicolla of soybean cultivar 92M02 at different plant growth stages. Within each experiment, means labeled with the same letter were not significantly different according to Tukey's test $(P<0.05)$.

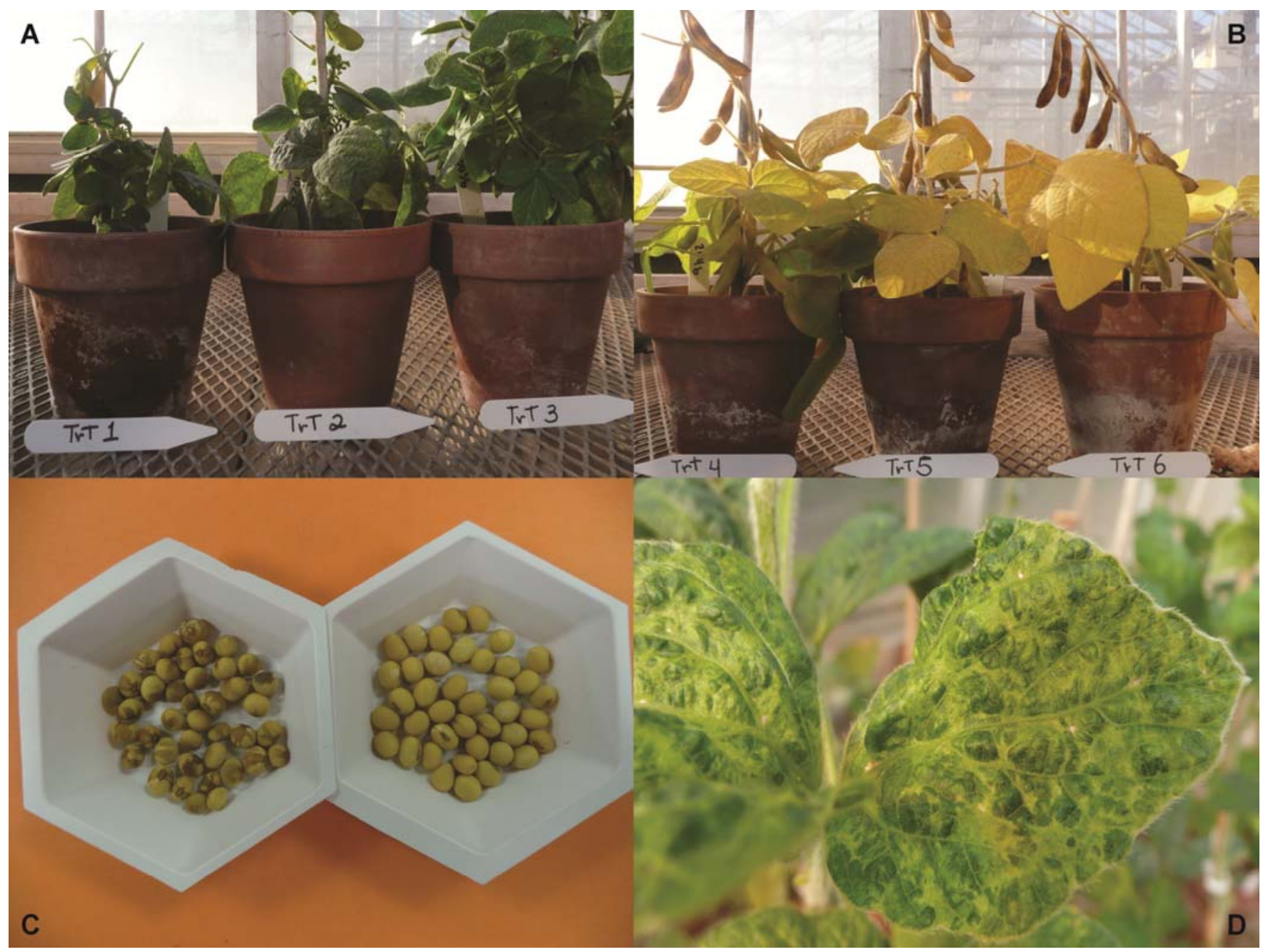

Fig. 3. Effects of Bean pod mottle virus (BPMV) treatments on soybean cultivar 92M02 (Pioneer Hi-Bred Int., Inc., Des Moines, IA). Top: Delay in senescence caused in A, BPMV-inoculated plants compared with B, BPMV noninoculated plants. Bottom: C, Seeds from BPMV-inoculated plants presenting seed coat mottling (left) compared with seeds from BPMV noninoculated plants (right). D, Foliar symptoms observed in BPMV-inoculated plants. 
corresponding to inoculations with $P$. longicolla consisted of inoculations at growth stages R3 and R5 in the first experiment, and inoculations at growth stages R5 and R7 in the second experiment, in addition to a noninoculated treatment. Each experiment was conducted twice.

The first repetition of the experiment including inoculations with P. longicolla at R3 and R5 was planted on 1 October 2009. Inoculations with $P$. longicolla were carried out at R3 and R5 on 15 November and 4 December, respectively. Plants were harvested on 21 January 2010. The second repetition was planted on 3 December 2009. Inoculations with $P$. longicolla were carried out at R3 and R5 on 22 February and 8 March 2010, respectively. Plants were harvested on 7 April 2010. The first repetition of the experiment corresponding to inoculations with $P$. longicolla at R5 and R7 was planted on 15 January 2010. Inoculations with $P$. longicolla were carried out at R5 and R7 on 16 April and 17 May, respectively. Plants were harvested on 15 June 2010. The second repetition was planted on 21 January 2010. Inoculations with $P$. longicolla were carried out at R5 and R7 on 26 April and 28 May, respectively. Plants were harvested on 25 June 2010.

The effect of SMV inoculations on infection by $P$. longicolla was studied in a separate experiment. This experiment followed the same procedure as the BPMV-Phomopsis experiment with cultivars Spansoy 201 and Colfax, described above. The first repetition of the experiment was planted on 19 May 2009. Inoculations with P. longicolla were carried out at R3 and R5 on 31 July and $25 \mathrm{Au}-$ gust, respectively. Plants were harvested on 25 September (Spansoy 201) and 5 October (Colfax) 2009. The second repetition was planted on 1 October 2009. Inoculations with P. longicolla were carried out at R3 and R5 on 18 December 2009 and 26 January 2010, respectively. Plants were harvested on 26 February 2010. The two cultivars were harvested at different times in the first replication of the experiment because of differing cultivar maturities.

Pathogen incidence assessments. When plants reached reproductive growth stages (R1 and R2), they were tested to confirm the presence of the viruses. The middle leaflet of the topmost fully expanded leaf from each soybean plant was sampled, placed in a plastic bag, and stored in a cooler for transportation. Sap was extracted using a leaf press (Ravenel Crop Specialties, Seneca, SC) as described by Byamukama et al. (4). Leaflets were individually placed between metal rollers, and Agdia extraction buffer was added while plant sap was collected into 5-ml portion cups (Instaoffice, Kennesaw, GA). Extracted sap was transferred to 1.5$\mathrm{ml}$ tubes, which were then frozen and stored at $-20^{\circ} \mathrm{C}$ for subsequent testing by double antibody sandwich enzyme-linked immunosorbent assay (DAS ELISA) using Agdia antibodies and protocol. For each sample, $100 \mu \mathrm{l}$ of leaf sap extract was placed in wells on the precoated ELISA plate. Two positive and negative controls were prepared and placed in each plate. Samples were evaluated with a PowerWave Microplate Spectrophotometer (Biotek Instruments, Inc., Winooski, VT) set at a wavelength of $405 \mathrm{~nm}$. A sample within a well was considered positive if absorbance values were higher than twice the values for the negative controls. For each treatment, an extra set of plants was kept under the same conditions in order to assure the availability of infected plants by the time of the fungal inoculations. These plants were also tested for viruses by ELISA. Any virus-inoculated plants that tested negative for the respective virus were replaced with plants that tested positive.

After all inoculations were carried out, plants were kept in the greenhouse and were hand harvested when virus noninoculated plants reached growth stage R8 (5). Stems were aseptically cut at the base of the plant, placed in a paper bag, and stored in the laboratory. For each replicate, stems and seeds were separated by hand and placed in individual paper envelopes.

For each treatment, 10 plants ( 2 plants/replicate) were evaluated for stem infection by $P$. longicolla using a stem plating test based on the procedure of Garzonio and McGee (6) with modifications. Stems were cut into sections (approximately $3 \mathrm{~cm}$ long), surface sterilized in $1 \%$ sodium hypochlorite for $1 \mathrm{~min}$, and rinsed in ster- ile distilled water for $30 \mathrm{~s}$. Under a laminar flow hood using aseptic technique, stem sections were then partitioned, and 10 pieces (approximately $1 \mathrm{~cm}$ each) from each plant were arbitrarily selected and five pieces per plate were placed on antibiotic-amended PDA in 9-cm-diameter petri dishes. After 5 to 7 days, plates were inspected for colonies of $P$. longicolla. If Phomopsis was observed from any section of a stem, that stem was considered infected, and the incidence of infected stems $(\%)$ per replicate was calculated.

To quantify seed infection by $P$. longicolla, culture plate testing was performed as described by Walcott (33). Twenty seeds from each replicate were arbitrarily selected, surface sterilized in $1 \%$ sodium hypochlorite for $30 \mathrm{~s}$, and rinsed in sterile distilled water for $30 \mathrm{~s}$. Under a laminar flow hood and using aseptic technique, five seeds per plate were placed on antibiotic-amended PDA in 9$\mathrm{cm}$-diameter petri dishes. After 5 to 7 days, plates were inspected for infection of seeds by $P$. longicolla. Morphological characteristics of the colonies and spores were used to identify P. longicolla colonies growing from stems and seeds as described by Kulik and Sinclair (17) and McGee (20).

Data analysis. Each experiment was conducted twice, and treatment-by-repetition interactions were not significant except for the incidence of stem infection in the experiments SMV-Phomopsis and the first BPMV-Phomopsis experiment with cultivar 92M02. Therefore, the data from both repetitions of each experiment were pooled, and treatment effects on incidence of stem and seed infections by $P$. longicolla were tested in a combined analysis using PROC GLM of SAS, version 9.2. Effects of treatments were estimated based on analysis of variance (ANOVA); mean separations were based on Tukey's test $(P<0.05)$. Residuals were examined using SAS PROC PLOT to determine if assumptions of normality were appropriate.

\section{Results}

In BPMV-Phomopsis experiments with cultivars Spansoy 201 and Colfax, inoculations with $P$. longicolla at both growth stages resulted in similar incidence of stem infection, but were significantly different from the $P$. longicolla noninoculated plants. There were no significant differences between cultivars $(P=0.157)$ or virus $(P=0.184)$ treatments (Table 1 and Fig. 1$)$. For seed infection, there were significant differences between cultivars $(P<$ $0.05)$, and significant main effects of BPMV inoculation $(P<0.05)$ and plant growth stage at inoculation with $P$. longicolla $(P<0.05)$. Moreover, there were significant interactions among the effects of cultivar and inoculation with $P$. longicolla $(P<0.05)$, BPMV and $P$. longicolla inoculations $(P<0.05)$, and cultivar, BPMV, and $P$. longicolla inoculations $(P<0.05)$ (Tables 1 and Fig. 1$)$. In these experiments, foliar symptoms were exhibited in BPMV-inoculated plants of both cultivars; but seed coat mottling of seeds was not observed in either cultivar. Although differences in plant maturity were observed between Spansoy 201 and Colfax, BPMV-inoculated and noninoculated plants from each cultivar did not differ in rate of development or maturation date.

Incidence of infected seeds by $P$. longicolla was approximately threefold higher in Colfax than in Spansoy 201 (Fig. 1). Plants of both cultivars inoculated with BPMV and P. longicolla at any of the two growth stages presented higher stem and seed infection by P. longicolla compared with the BPMV noninoculated plants (Fig. 1 ); however, this effect was not always statistically significant. In addition, when $P$. longicolla was inoculated at growth stage R5, more seed infection by $P$. longicolla occurred compared with the seed harvested from plants inoculated at R3 and the P. longicolla noninoculated plants (Fig. 1). The virus effect was significant only in Spansoy 201, and seed infection by P. longicolla was approximately 1.7-fold higher in the BPMV-inoculated plants (49\%), compared with the BPMV noninoculated plants (29\%), when both were inoculated with the fungus at R5 (Fig. 1).

In the first BPMV-Phomopsis experiment with cultivar 92M02, there were differences in stem infection by $P$. longicolla $(P<0.05)$ between plants that were inoculated or not inoculated with the fungus. Moreover, there were differences in seed infection by $P$. 
longicolla between treatments that included inoculations with either BPMV $(P<0.05)$ or $P$. longicolla $(P<0.05)$ (Table 2$)$. Neither stem nor seed infection were affected by the growth stage (R3 and R5) in which P. longicolla inoculations were conducted. However, there was a significant interaction between the effects of BPMV inoculation and $P$. longicolla inoculation on seed infection $(P<0.05)$ (Table 2). Compared with the BPMV noninoculated plants $(\mathrm{R} 3=19.5 \%, \mathrm{R} 5=19 \%)$, BPMV-infected plants were more susceptible to seed infection by $P$. longicolla when they were inoculated with P. longicolla at growth stages R3 (38.5\%) and R5 (37\%) (Fig. 2).

In the second experiment with 92M02, there were significant differences in seed infection by $P$. longicolla between treatments that included inoculations with either BPMV $(P<0.05), P$. longicolla $(P<0.05)$, or both $(P<0.05)$ (Table 2$)$. There were also differences in stem infection by $P$. longicolla between plants that were inoculated or not inoculated with the fungus. In addition, higher incidence of stem and seed infection by $P$. longicolla was observed when plants were inoculated with the fungus at growth stage R7 compared with plants inoculated at R5. Virus inoculation significantly enhanced seed infection by $P$. longicolla at both growth stages, R5 and R7, compared with the BPMV noninoculated plants (Fig. 2).

In both experiments with 92M02, all the BPMV-inoculated plants displayed typical BPMV foliar symptoms, seed coat mottling of seeds, and a delay in maturity (Fig. 3). In addition, the number of seeds was slightly lower in BPMV-inoculated plants compared with noninoculated plants; however, these differences were not significant in either of the experiments (data not shown).

In SMV-Phomopsis experiments with cultivars Spansoy 201 and Colfax, there were significant differences in stem infection by $P$. longicolla between cultivars $(P<0.05)$ and the plant growth stage when inoculations with $P$. longicolla were performed $(P<$ 0.05 ) (Table 3). Infection of stems and seeds by $P$. longicolla were higher when plants were inoculated at growth stage R5, compared with inoculations at R3 and noninoculated plants (Fig. 4). In both cultivars, stem infection was approximately 1.5 -fold higher in R5inoculated plants than in plants inoculated at R3. In addition, incidence of $P$. longicolla infection was 2.3 - and 6.5-fold higher in seeds harvested from late-inoculated plants of Spansoy 201 and Colfax, respectively. However, SMV inoculations did not increase stem or seed infection by $P$. longicolla compared with the SMV noninoculated plants (Fig. 4). Even though SMVinoculated plants tested positive for virus infection, foliar symptoms were inconsistently observed, and seed coat mottling of seeds was not observed. As in the BPMV-Phomopsis experiment with Spansoy 201 and Colfax, there were differences in cultivar maturities, but these differences were independent of the virus inoculation treatment.

Table 3. Analysis of variance (ANOVA) for effects of soybean cultivar, Soybean mosaic virus (SMV), and Phomopsis longicolla inoculation treatments on infection of stems and seeds by $P$. longicolla ${ }^{\mathrm{a}}$

\begin{tabular}{lccc}
\hline & & \multicolumn{2}{c}{$P$ value } \\
\cline { 3 - 4 } Source & df & Stems & Seeds \\
\hline Repetition & 1 & $<0.05$ & 0.076 \\
Block & 4 & 0.830 & 0.999 \\
Cultivar $^{\mathrm{b}}$ & 1 & $<0.05$ & 0.487 \\
SMV $^{\mathrm{y}}$ & 1 & 0.209 & 0.528 \\
$P$. longicolla & 2 & $<0.05$ & $<0.05$ \\
Cultivar $\times$ SMV & 1 & 0.409 & 0.154 \\
Cultivar $\times$ P. longicolla & 2 & 0.101 & 0.072 \\
SMV $\times$ P. longicolla & 2 & 0.612 & 0.339 \\
Cultivar $\times$ SMV $\times$ P. longicolla & 2 & 0.263 & 0.093 \\
\hline
\end{tabular}

${ }^{a}$ Data are from two repetitions of a greenhouse experiment.

${ }^{b}$ Two cultivars tested: Spansoy 201 and Colfax.

${ }^{\mathrm{c}}$ SMV treatments: inoculated or noninoculated.

${ }^{\mathrm{d}} P$. longicolla treatments: Inoculation at growth stage R3 or R5 and noninoculated.

\section{Discussion}

To our knowledge, this study is the first to evaluate the effect of SMV and BPMV on susceptibility to $P$. longicolla infection on soybean plants under controlled conditions. Soybean stems were susceptible to infection by $P$. longicolla when plants were inoculated at either growth stage R3 or R5, irrespective of the soybean cultivar or the virus inoculation treatment. These results suggest that under the conditions of this study, neither SMV nor BPMV significantly increased susceptibility to stem infection by $P$. longicolla.

The effect of BPMV infection on susceptibility to seed infection by $P$. longicolla differed among cultivars. In Spansoy 201, inoculation with BPMV significantly increased susceptibility to seed infection by $P$. longicolla only in plants inoculated with $P$. longicolla at growth stage R5. However, this effect was not observed on Colfax. In 92M02, BPMV-inoculated plants were more susceptible to seed infection by P. longicolla at growth stages R3, R5, and R7.

The results with Spansoy 201 and 92M02 are consistent with previous studies reporting the increased incidence of Phomopsis spp. in seeds from BPMV-infected plants (1). Unlike in previous studies, the effect of BPMV on seed infection by $P$. longicolla observed in this study was independent from the effects that beetle vectors of BPMV can have in pod and seed infection by Phomopsis spp. $(23,28,31)$. These results confirm that even in the absence of insect damage, BPMV infection alone increases susceptibility to seed infection by $P$. longicolla $(17,29)$.

Our data suggest that BPMV-induced predisposition to P. longicolla is not due solely to prolonging seed maturation. In this study, delayed senescence in BPMV-inoculated plants was observed only in cultivar 92M02 (Fig. 4). Abney and Ploper (1) consistently observed an effect of BPMV increasing seed infection by Phomopsis spp. only if the virus infection delayed the rate of seed maturation. However, in our study, seed infection by P. longicolla of Spansoy 201 was increased even in the absence of any effect on plant maturation. In addition, BPMV infection enhanced seed infection by $P$. longicolla in cultivar 92M02, regardless of plant development stage at inoculation, even when the fungus was inoculated as early as R3. This suggests that BPMV increases pod susceptibility, as reported by Abney and Ploper (1), and higher seed infection might simply be due to a higher proportion of pods being infected. Koning et al. (16) speculated that the mechanism by which prolonged maturity predisposed virus-infected plants to Phomopsis spp. was due to longer exposure of the pods and seeds to weather conditions favorable for seed infection. Abney and Ploper (1) speculated that the mechanism was longer moisture retention in seeds of BPMV-infected plants. In our study, neither hypothesis

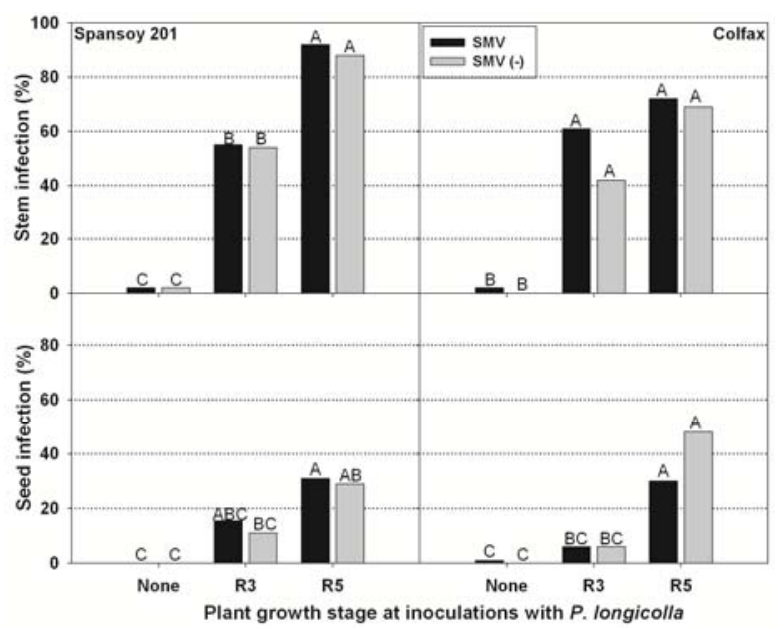

Fig. 4. Effects of Soybean mosaic virus (SMV) and Phomopsis longicolla inoculation treatments on infection of stems (top) and seeds (bottom) by P. longicolla of two soybean cultivars, SMV-susceptible Spansoy 201 (left) and SMV-tolerant Colfax (right) at different plant growth stages. Within each cultivar, means labeled with the same letter were not significantly different according to Tukey's test $(P<0.05)$. 
would explain the increased susceptibility because plants were exposed to high humidity (plastic bag covering) for only one brief period during seed maturation. It is unlikely that pod-to-seed movement of $P$. longicolla occurred after that period, because high temperature and relative humidity conditions are required for podto-seed movement $(2,26)$; and this study was conducted under constant environmental conditions. Koning et al. (16) also noted that virus-induced predisposition occurred in some years when there was no effect of virus infection on plant maturity.

Inoculation with SMV did not increase the incidence of seed infection by $P$. longicolla. Similar results were reported by Stuckey et al. (32), who reported that SMV had no effect on seed infection by Phomopsis spp. and found a significant increase in Phomopsis spp. only in plants co-infected with SMV and BPMV. These results are not consistent with those of other investigators $(8,15,16)$, who found that SMV infection increases seed infection by Phomopsis spp. These disagreements in results might be due to differences in the SMV strain used, or because of the soybean cultivars chosen for the study. In previous studies, only highly virulent SMV isolates caused an increase in seed infection by Phomopsis spp., and the effect differed among cultivars $(8,15,16)$.

Koning et al. (16) observed a significant increase in seed infection by Phomopsis spp. due to inoculations with a SMV-G2 strain, which was likely to cause an extension of the seed development interval in SMV-susceptible cultivars. In the current study, neither an increase in seed infection nor a delay in senescence was observed in Spansoy 201 or Colfax as a response to infection by the SMV-G2 strain used. Differences in virulence between SMV isolates within strain SMV-G2 may have caused the inconsistency in results. Moreover, this study evaluated the effect of SMV on infection by $P$. longicolla, which differs from previous studies that have reported the effect of SMV on infection by either Phomopsis spp. $(15,16,32)$ or $P$. sojae Lehm. $(8,25)$.

Even though it has been reported (11) that soybean cultivars Spansoy 201 and Colfax are tolerant to BPMV and SMV, respectively, in this study both cultivars were infected by both viruses when plants were mechanically inoculated at early growth stages (V1 to V2). This was not surprising because the previously reported tolerance was based on parameters that were not considered in this experiment, such as relative level of virus antigen in seed and mottling of soybean seed coats. In addition, Wang et al. (34) reported that Colfax was resistant to SMV-G1 but susceptible to SMV-G5, and it is possible that it is also susceptible to the SMVG2 strain used in this study.

The incidence of seed infection by P. longicolla in Spansoy 201 and Colfax tended to be higher when plants were inoculated at R5, compared with inoculations at R3. In cultivar 92M02, there were no significant differences between inoculations with $P$. longicolla at growth stage R3 and R5, but seed infection was significantly higher when plants were inoculated at R7 compared with plants inoculated at R5. Nevertheless, in all three cultivars, seed infection occurred when plants were inoculated at any growth stage. In this study, plants were covered with a plastic bag to keep a humid environment after each inoculation with $P$. longicolla to enhanced pod infection and again at beginning of maturity to enhance conditions for infection of seeds. Previous studies have reported that under field conditions major seed infection will not occur before physiological maturity $(17,19,26)$ and only under particular conditions of humidity and temperature $(2,26)$.

Although the predisposing effect of plants infected with either SMV or BPMV to seed infection by Phomopsis spp. has been well documented, the mechanisms underlying these interactions are still not completely understood. However, our data suggest that delayed plant maturity is not the sole mechanism. Future studies should focus on the effects of $P$. longicolla inoculations on plants coinfected with both SMV and BPMV.

\section{Acknowledgments}

We thank John Hill, Alan Eggenberger, Chunquan Chris Zhang, Emmanuel Byamukama, Sharon Eggenberger, and Dave Volkers for their assistance and cooperation in this study. In addition, we thank Phillip Dixon and Adam Pintar, ISU Department of Statistics, for their assistance with data analysis. We are grateful to the Iowa Soybean Association for funding to support this project.

\section{Literature Cited}

1. Abney, T. S., and Ploper, L. D. 1994. Effects of bean pod mottle virus on soybean seed maturation and seedborne Phomopsis spp. Plant Dis. 78:3337 .

2. Balducchi, A. J., and McGee, D. C. 1987. Environmental factors influencing infection of soybean seeds by Phomopsis and Diaporthe species during seed maturation. Plant Dis. 71:209-212.

3. Bradshaw, J. D., Rice, M. E., and Dorhout, D. 2006. Bean leaf beetles return-with a vengeance. Integrated Crop Management newsletter, IC 496:120-121. Iowa State University, Ames, IA.

4. Byamukama, E., Robertson, A. E., and Nutter, F. W., Jr. 2010. Quantification of temporal and spatial dynamics of Bean pod mottle virus at different spatial scales. Online. Plant Health Progress doi:10.1094/PHP-2010-052603-SY.

5. Fehr, W. R., Caviness, C. E., Burmood, D. T., and Pennington, J. S. 1971. Stage of development descriptions for soybeans, Glycine max (L.) Merrill. Crop Sci. 11:929-931.

6. Garzonio, D. M., and McGee, D. C. 1983. Comparison of seeds and crop residues as sources of inoculum for pod and stem blight of soybeans. Plant Dis. 67:1374-1376.

7. Gergerich, R. C. 1999. Bean pod mottle virus. Pages 61-62 in: Compendium of Soybean Diseases. 4th ed. G. L. Hartman, J. B. Sinclair, and J. C. Rupe, eds. American Phytopathological Society, St. Paul, MN.

8. Hepperly, P. R., Bowers, G. R., Jr., Sinclair, J. B., and Goodman, R. M. 1979. Predisposition to seed infection by Phomopsis sojae in soybean plants infected by soybean mosaic virus. Phytopathology 69:846-848.

9. Hepperly, P. R., and Sinclair, J. B. 1978. Quality losses in Phomopsis infected soybean seeds. Phytopathology 68:1684-1687.

10. Hill, J. H. 1999. Soybean mosaic virus. Pages 70-71 in: Compendium of Soybean Diseases. 4th ed. G. L. Hartman, J. B. Sinclair, and J. C. Rupe, eds. American Phytopathological Society, St. Paul, MN.

11. Hill, J. H., Koval, N. C., Gaska, J. M., and Grau, C. R. 2007. Identification of field tolerance to Bean pod mottle and Soybean mosaic viruses in soybean. Crop Sci. 47:212-218.

12. Hill, J. H., Pedersen, P., and Bradshaw, J. 2006. Bean pod mottle virus: Back with a vengeance. Integrated Crop Management newsletter, IC496:223. Iowa State University, Ames, IA.

13. Hobbs, H. A., Hartman, G. L., Wang, Y., Hill, C. B., Bernard, R. L., Pedersen, W. L., and Domier, L. L. 2003. Occurrence of seed coat mottling in soybean plants inoculated with Bean pod mottle virus and Soybean mosaic virus. Plant Dis. 87:1333-1336.

14. Hobbs, T. W., Schmitthenner, A. F., and Kuter, G. A. 1985. A new Phomopsis species from soybean. Mycologia 77:535-544.

15. Koning, G., TeKrony, D. M., Ghabrial, S. A., and Pfeiffer, T. W. 2002. Soybean mosaic virus (SMV) and the SMV resistance gene $\left(\mathrm{Rsv}_{1}\right)$ influence on Phomopsis spp. seed infection in an aphid free environment. Crop Sci. 42:178-185.

16. Koning, G., TeKrony, D. M., Pfeiffer, T. W., and Ghabrial, S. A. 2001. Infection of soybean with soybean mosaic virus increases susceptibility to Phomopsis spp. seed infection. Crop Sci. 41:1850-1856.

17. Kulik, M. M., and Sinclair, J. B. 1999. Phomopsis seed decay. Pages 31-32 in: Compendium of Soybean Diseases. 4th ed. G. L. Hartman, J. B. Sinclair, and J. C. Rupe, eds. American Phytopathological Society, St.Paul, MN.

18. Lu, X., Robertson, A. E., Byamukama, E. Z., and Nutter, F. W., Jr. 2010 Evaluating the importance of stem canker of soybean in Iowa. Plant Dis. 94:167-173.

19. McGee, D. C. 1986. Prediction of Phomopsis seed decay by measuring soybean pod infection. Plant Dis. 70:329-333.

20. McGee, D. C. 1992. Soybean Diseases: A Reference Source for Seed Technologists. American Phytopathological Society, St. Paul, MN

21. Mengistu, A., Castlebury, L., Smith, R., Ray, J., and Bellaloui, N. 2009. Seasonal progress of Phomopsis longicolla infection on soybean plant parts and its relationship to seed quality. Plant Dis. 93:1009-1018.

22. Meriles, J. M., Lamarque, A. L., Labuckas, D. O., and Maestri, D. M. 2004 Effect of fungal damage by Fusarium spp. and Diaporthe/Phomopsis complex on protein quantity and quality of soybean seed. J. Sci. Food Agric. 84:1594-1598.

23. Obopile, M., and Hammond, R. B. 2001. Effects of delayed harvest on soybean seed quality following bean leaf beetle (Coleoptera: Chrysomelidae) pod injury. J. Kansas Entomol. Soc. 74:40-48.

24. Redinbaugh, M. G., Molineros, J. E., Vacha, J., Berry, S. A., Hammond, R. B., Madden, L. V., and Dorrance, A. E. 2010. Bean pod mottle virus spread in insect-feeding-resistant soybean. Plant Dis. 94:265-270.

25. Ross, J. P. 1977. Effect of aphid-transmitted Soybean mosaic virus on yields of closely related resistant and susceptible soybean lines. Crop Sci. 17:869-872.

26. Rupe, J. C. 1990. Effect of temperature on the rate of infection of soybean seedlings by Phomopsis longicolla. Can. J. Plant Pathol. 12:43-47.

27. Rupe, J. C., and Ferriss, R. S. 1987. A model for predicting the effects of microclimate on infection of soybean by Phomopsis longicolla. Phytopathology 77:1162-1166. 
28. Shortt, B. J., Sinclair, J. B., Helm, C. G., Jeffords, M. R., and Kogan, M. 1982. Soybean seed quality losses associated with bean leaf beetles and Alternaria tenuissima. Phytopathology 72:615-618.

29. Sinclair, J. B. 1993. Phomopsis seed decay of soybeans-A prototype for studying seed disease. Plant Dis. 77:329-334.

30. Sinclair, J. B. 1999. Diaporthe-Phomopsis complex. Page 31 in: Compendium of Soybean Diseases. 4th ed. G. L. Hartman, J. B. Sinclair, and J. C. Rupe, eds. American Phytopathological Society, St.Paul, MN.

31. Smelser, R. B., and Pedigo, L. P. 1992. Soybean yield and quality reduction by bean leaf beetle (Coleoptera: Chrysomelidae) pod injury. J. Econ. Entomol. 85:2399-2403.

32. Stuckey, R. E., Ghabrial, S. A., and Reicosky, D. A. 1982. Increased incidence of Phomopsis sp. in seeds from soybeans infected with bean pod mottle virus. Plant Dis. 66:826-829.

33. Walcott, R. R. 2003. Acidified PDA method for the detection of Phomopsis complex on Glycine max. International Rules for Seed Testing, Chapter 7: Seed health testing methods 7-016. International Seed Testing Association (ISTA), Bassersdorf, Switzerland.
34. Wang, Y., Hobbs, H. A., Hill, C. B., Domier, L. L., Hartman, G. L., and Nelson, R. L. 2005. Evaluation of ancestral lines of U.S. soybean cultivars for resistance to four soybean viruses. Crop Sci. 45:639-644.

35. Wrather, A., Shannon, G., Balardin, R., Carregal, L., Escobar, R., Gupta, G. K., Ma, Z., Morel, W., Ploper, D., and Tenuta, A. 2010. Effect of diseases on soybean yield in the top eight producing countries in 2006. Online. Plant Health Progress doi:10.1094/PHP-2010-0125-01-RS.

36. Wrather, J. A., Sleper, D. A., Stevens, W. E., Shannon, J. G., and Wilson, R. F. 2003. Planting date and cultivar effects on soybean yield, seed quality, and Phomopsis sp. seed infection. Plant Dis. 87:529-532.

37. Yang, X. B. 1999. Seedborne diseases of soybean 1999. Integrated Crop Management newsletter, IC-482:23-24. Iowa State University, Ames, IA.

38. Zhang, A. W., Hartman, G. L., Curio-Penny, B., Pedersen, W. L., and Becker, K. B. 1999. Molecular detection of Diaporthe phaseolorum and Phomopsis longicolla from soybean seeds. Phytopathology 89:796-804.

39. Ziems, A. D., Giesler, L. J., Graef, G. L., Redinbaugh, M. G., Vacha, J. L., Berry, S. A., Madden, L. V., and Dorrance, A. E. 2007. Response of soybean cultivars to Bean pod mottle virus infection. Plant Dis. 91:719-726. 